\title{
Meeting the Editorial Board Member of PRPM: Professor Luis A. López-Fernández
}

\author{
Grace S. Li, Jane Huang \\ PRPM Editorial Office, AME Publishing Company \\ Correspondence to: Grace S. Li; Jane Huang. PRPM Editorial Office, AME Publishing Company. Email: prpm@amegroups.com.
}

Received: 30 November 2021; Accepted: 13 December 2021.

doi: 10.21037/prpm-2021-01

View this article at: https://dx.doi.org/10.21037/prpm-2021-01

\section{Expert introduction}

Professor Luis A. López-Fernández, $\mathrm{PhD}$ is a Senior Researcher and head of the Laboratory of Pharmacogenetics and Pharmacogenomics, Hospital Gregorio Marañón. He is also a member of the Hospital Pharmacy and Pharmacogenomics group of research at Gregorio Marañón Health Research Institute, the Spanish Clinical Research Network (SCReN), Hospital Gregorio Marañón Medicines Research Ethics Committee. He is a member of the board of the Spanish Society of Pharmacogenetics and Pharmacogenomics (SEFF), and a member of the Spanish Association for Human Genetics (AEGH).

He has published over 90 peer-reviewed research papers many of which are in high caliber journals in the fields of Pharmacy and Pharmacology, Oncology, Genetics and Virology. Dr. López-Fernández is a health researcher with extensive training in genetics, genomics, and molecular biology. He has joined the editorial board of Pharmacogenomics Research and Personalized Medicine since May 2021.

The López-Fernandez laboratory's main research focus is translational pharmacogenomics with particular interest in the pharmacogenomics of fluoropyrimidines, therapeutic drug monitoring and pharmacogenomics of inflammatory bowel disease, and pharmacogenomics of multiple sclerosis. Dr. López-Fernández leads a multi-disciplinary team that consists of hospital pharmacists, biologists, geneticists, physicians, and neurologist to identify new biomarkers and apply them in clinical practice.

\section{Interview}

PRPM: What do you think is the role of pharmacogenetics in internal disease treatment?

Prof. López-Fernández: I believe that pharmacogenetics can be extremely useful in personalizing treatments in internal medicine diseases. The use of pharmacogenetics can help to select the best treatment and, in addition, to avoid serious unwanted drug-related adverse events. Most of these internal diseases are age-related and polymedication in these patients is a very interesting challenge for pharmacogenetics. Recent findings indicate that most of these patients take drugs with pharmacogenetic biomarkers. The application of pharmacogenetics in these types of patients is an exciting challenge.

\section{PRPM: How do you perceive the opportunity for interdisciplinarity in the field of pharmacogenetics?}

Prof. López-Fernández: Pharmacogenetics is a perfect example of interdisciplinarity. The application of pharmacogenetics requires teams with doctors, pharmacists, biologists, geneticists, etc. The coordinated action of all these actors is mandatory and patient reports should reflect both the basis of the genetic test and the accuracy of the result, as well as the implications of this result on the 
efficacy/safety of the drug and clinical recommendations for the patient.

PRPM: Would you like to give us a general picture on the publication area in pharmacogenomics? Any topics or paper impressed you most in the past two years?

Prof. López-Fernández: The area of pharmacogenetics publication has changed in recent years. Between 2000 and 2015, pharmacogenetics manuscripts were easily published and expectations for clinical translation were too high. Today, the requirements for publication of pharmacogenetic advances are tougher and manuscripts are more robust. One of the papers that impressed me most was a recent UK biobank analysis showing that $99.5 \%$ of individuals can have an atypical response to at least one drug by analyzing only 14 genes (McInnes et al., Clin Pharmacol Ther 2021) (1).

PRPM: Can you tell us about any new and exciting projects you're working on? What do you foresee as the next step in your research journey?

Prof. López-Fernández: In our group we work on three main lines of research in pharmacogenetics/ pharmacogenomics. The first one is on chemotherapyinduced toxicity in solid tumors, mainly focused on fluoropyrimidines and their main metabolizing gene, DPYD. In this line of research, we identified genetic variants associated with fluoropyrimidine-induced toxicity and described for the first time two of these mutations. We are now studying the association between phenotype and genotype in these patients. In the second line of research, we are looking for pharmacogenomic biomarkers of response to anti-tumor necrosis factor drugs in pediatric inflammatory bowel disease to create a score to help us select the best treatment in this chronic disease. Finally, we are also working on finding biomarkers of response to treatments used in multiple sclerosis and trying to understand the mechanisms of action.

The next step in my research journey is to translate all these biomarkers and knowledge into clinical practice. For this goal, we need to collaborate with other groups in coordinated projects.

PRPM: During research, what are the biggest challenges/ problems you had faced? And bow would you sort them out?

Prof. López-Fernández: In my experience, the main problem I have faced is financial support for research and the stability of research positions. In Spain it is a real problem and grants do not usually include a portion for pre- or postdoctoral positions. The only way to solve this problem is to work, work and work.

PRPM: As an Editorial Board Member of PRPM, what is your expectation for PRPM?

Prof. López-Fernández: The scope of the PRMP is really clear and fits my lines of research and experience. However, the point that decided me to participate in this project is the extraordinary level of the editorial board. This is a guarantee of success and I am happy to be part of it. I hope that PRMP will be one of the most relevant journals in pharmacogenetics in a few years.

\section{PRPM: PRPM is adbering to high publication standards and transparency from the start (bttps://prpm.amegroups. com/article/view/51187/pdf). Would you like to share your perspectives at this point?}

Prof. López-Fernández: High standards and transparency are essential to achieve a high-quality magazine. In this sense, PRPM's adherence to these standards guarantees its success. I am confident that PRPM will be one of the most relevant journals in the field of pharmacogenetics in the near future.

\section{Acknowledgments}

We would like to thank Prof. Luis A. López-Fernández for sparing time for the interview.

Funding: None.

\section{Footnote}

Provenance and Peer Review: This article was commissioned by the editorial office, Pharmacogenomics Research and Personalized Medicine for the series "Meet the Professor". The article did not undergo external peer review.

Conflicts of Interest: Both authors have completed the ICMJE uniform disclosure form (available at https:// dx.doi.org/10.21037/prpm-2021-01). The series "Meet the Professor" was commissioned by the editorial office without any funding or sponsorship. GSL and JH report that they are full-time employees of AME publishing company 
(publisher of the journal). The authors have no other conflicts of interest to declare.

Open Access Statement: This is an Open Access article distributed in accordance with the Creative Commons Attribution-NonCommercial-NoDerivs 4.0 International License (CC BY-NC-ND 4.0), which permits the noncommercial replication and distribution of the article with the strict proviso that no changes or edits are made and the

doi: $10.21037 / \mathrm{prpm}-2021-01$

Cite this article as: Li GS, Huang J. Meeting the Editorial

Board Member of PRPM: Professor Luis A. López-Fernández.

Pharmacogenomics Res Pers Med 2021. original work is properly cited (including links to both the formal publication through the relevant DOI and the license). See: https://creativecommons.org/licenses/by-nc-nd/4.0/.

\section{References}

1. McInnes G, Lavertu A, Sangkuhl K, et al.

Pharmacogenetics at Scale: An Analysis of the UK

Biobank. Clin Pharmacol Ther 2021;109:1528-37. 